\title{
MEDIA COMPANY PROFILE BERBENTUK DESAIN BOOKLET MENGGUNAKAN APLIKASI PHOTOSHOP CS5 DI PT. CITRA SURYA SELARAS BERBASIS MULTIMEDIA
}

\author{
Dedi Martono ${ }^{1}$ \\ Al Husain ${ }^{2}$ \\ Devi Iswara ${ }^{3}$ \\ Dosen STMIK Raharja ${ }^{1,2}$, STMIK Raharja Jurusan Teknik Informatika ${ }^{3}$ \\ Jl. Jendral Sudirman No. 40, Modernland, Kota Tangerang ${ }^{1,2,3}$ \\ Email : dedi@raharja.info ${ }^{1}$, alhusain@ raharja.info $^{2}$, devi.iswara@raharja.info ${ }^{3}$
}

\begin{abstract}
ABSTRAK
Dalam sebuah perkembangan Ilmu dan Teknologi yang semakin maju telah membawa pengaruh besar di segala bidang, termasuk dalam bidang multimedia. Company Profile merupakan media informasi dan promosi dalam perusahaan untuk menyampaikan sebuah nilai yang positif untuk suatu perusahaan. Demikian yang diperlukan oleh PT. Citra Surya Selaras dalam memberikan informasi dan promosi melalui media berbentuk desain booklet dengan menggunakan sebuah aplikasi Photoshop CS5 salah satunya adalah perkembangan media promosi yang digunakan sebagai alat bantu komunikasi dalam penyampaian yang dirancang menjadi bentuk media yang lebih spesifik dan berguna bagi masyarakat. Tujuan dari penelitian ini dapat membuat sebuah media informasi dan promosiberupa bentuk desain booklet dalam Company Profile dengan mengunakan aplikasi Photoshop CS5 yang akan diterapkan pada PT. Citra Surya Selaras sebagai sarana promosi dan memberikan informasi mengenai seputar perusahaan tersebut. Metode yang digunakan adalah photoshop CS5. Dengan media yang berbentuk desain booklet pada Company Profile di PT. Citra Surya Selaras untuk memudahkan user dapat mengetahuiperkembangan informasiyang diberikan oleh perusahaan dan memudahkan perusahaan dalam media promosi keinginan supaya dapat berguna dan memiliki nilai tambah dalam media promosi pada PT. Citra Surya Selaras. Demikian dibuatnya media informasi dan promosi Company Profile yang dapat menggambarkan suatu profil perusahaan secara teriperinci dan lengkap. Salah satu elemen penting selalu diperhatikan oleh perusahaan, untuk menghadapi persaingan.
\end{abstract}

Kata Kunci: Company Profile, Media Promosi dan iformasi, Photoshop CS5, Desain Booklet

\begin{abstract}
In the development of advanced science and technology has brought great influence in all fields, including in the field of multimedia. Company Profile is a medium of information and promotion within the company to convey a positive value for the company. That's what PT. Citra Surya Selaras in providing information and promotion through the media shaped booklet design using Photoshop CS5 application one of which is the development of promotional media used as a communication tool in the delivery of which is designed to be a more specific media and useful for the community. The purpose of this research is to develop information and promotion media in the form of booklet design in Company Profile by using Photoshop CS5 application that will be applied to PT. Citra Surya Selaras as a means of promotion and provide information about the company. The method used is photoshop CS5. With the media in the form of booklet design on Company Profile in PT. Citra Surya Selaras to facilitate users in the desire of media to be useful and have added value in the media at PT. Citra Surya Selaras. Thus creating media information and Company Profile promotions that can describe the company's complete and detailed profile. One important element is always considered by the company, to face competition.
\end{abstract}

Keywords: Company Profile, Media Promotion and infomation, Photoshop CS5, Booklet Design 


\section{PENDAHULUAN}

Dalam perkembangan Ilmu dan Teknologi yang semakin berkembang telah membawa pengaruh besar di segala bidang, di antaranya dalam sebuah Media Informasi dan Promosi. Sehingga dibutuhkan sebuah sistem yang berkualitas untuk menghadapi persingan perusahaan untuk perkembangan dan kemajuan usahanya. Demikian dibuatnya media informasi dan promosi Company Profile berbentuk desain booklet yang dapat menggambarkan suatu profil perusahaan secara lengkap dan terperinci. Salah satu elemen penting selalu diperhatikan oleh perusahaan, untuk menghadapi persainganglobal adalah sebagaimana peruasaahan memberikan sebuah informasi dan promosi yang berkualitas dan produktivitas.

PT. Citra Surya Selaras adalah sebuah peusahaan yang bergerak dalam bidang produksi jam dinding kayu eksklusif untuk promosi dan packaging box kertas. Perusahaan tersebut membutuhkan sebuah media informasi dan promosi company profile untuk menjelaskan lebih rinci tetang gambaran PT. Citra Surya Selaras. Permasalahan pada PT.Citra Surya Selaras adalah dimana informasi dan promosi yang kurang efektif dalam menampilkan gambaran-gambaran umum tentang perusahaan yang belum diterapkan dalam media company profile. Sehingga banyak masyarakat yang tidak tahu tentang gambaran perusahaan tersebut. Dengan demikian susunannya "Media Company Profile Berbentuk Desain Booklet Menggunakan Aplikasi Photoshop CS5 Di PT. Citra Surya Selaras Berbasis Multimedia"ini diharapkan agar masyarakat dapat lebih mudah mengetahui perkembangan perusahaan tersebut dengan baik. Serta memudahkan perusahaan dalam melakukan sebuah promosi yang akan datang.

Kemajuan teknologi saat ini sangatlah mempengaruhi berbagai segi bidang kehidupan, di antaranya dunia bisnis pola kehidupan masyarakat mau pun teknologi informasi yang bagian penting dalam aktivitas proses bisnis agar dapat bersaing secara berkesinambungan. Dengan adanya perubahan ini menyebabkan perkembangan dalam dunia usaha semakin pesat yang menimbulkan persaingan yang ketat antara perusahan dan menjaring konsumen. Program-program atau tindakan-tindakan yang harus segera dilakukan agar dapat menarik minat masyarakat untuk media promosi dan informasi pada PT.Citra Surya Selaras agar mempertahankan kelangsungan hidup perusahaan. Perkembangan teknologi promosi dan informasi khususnya teknologi multmedia yang seperti dunia bisnis sebagai media prestasi. Data sekunder merupakan data yang sudah tersedia sehingga kita dapat mencari dan mengumpulkan data,metode pengumpulan menggunakan aplikasi Photoshop CS5 dalam penelitian, teknik pengumpulan data merupakan sebuah faktor penting untuk pencapaian keberhasilan dalam penelitian. Hal ini berkaitan dengan bagaimana cara mengumpulkan data, siapa sumbernya, dan apa alat yang digunakan. Data diperoleh dari sumber tidak langsung (data sekunder).

\section{RUMUSAN MASALAH}

Bagaimana agar merancang media yang lebih dapat menjelaskan secara rinci mengenai profil perusahaan, dan bagaimana membentuk media penunjang promosi yang lebih baik dalam persaingan perusahaan prosedur sistem yang sedang berjalan saat ini pada media informasi dan promosi pada PT.Citra Surya Selaras masih berjalan secara semi komputerisasi. Seperti mengadakan promosi-promosi diluar perusahaan yang memberikan informasi secara langsung kepada user melalui presentasi. Sehigga banyak user yang tidak mengetahui adanya produk-produk baru yang dikeluarkan oleh perusahaan yang akan dipromosikan. Sehingga informasi yang didapat oleh user tidak efektif tujuan untuk mengetahui sistem yang sedang berjalan mengenai proses company profile pada PT.Citra Surya Selaras, untuk membentuk company profile yang lebih menarik perhatian kepada 
pelanggan, manfaat memudahkan pelanggan dalam memperhatikan perkembangan perusahaan memberikan sarana promosi dan informasi dengan jelas dan efisien.

\section{PEMECAHAN MASALAH}

Setelah mengamati dan meneliti dari beberapa permasalahan yang terjadi pada PT.Citra Surya Selaras, Untuk mengatasi berbagai masalah tersebut, maka diperlukan sebuah sistem yang efektif serta efisien dalam melakukan media promosi dan informasi. Dari rumusan masalah tersebut bagaimana PT. Citra Surya Selaras mempromosikan secara jelas dan lengkap mencakup seluruh informasi yang mengenai Company Profile dengan menggunakan aplikasi Photoshop CS5 maka diharapkan company profile yang berbentuk desain booklet dapat meningkatkan nilai positif pada PT.Citra Surya Selaras, menjadi solusi promosi dan informasi menggunakan fasilitas aplikasi photoshop Cs5. Pada pemecahan masalah menggunakan metode observasi, wawancara, dan study pustaka.

\section{LITERATUR RIVIEW}

Literature reviewadalah bahan yang tertulis berupa buku, jurnal yang membhas tentang topic tyang akan diteliti ([Menurut Hermawan 2009:45]). Banyaknya penelitian yang sebelumnya dilakukan mengenai Company Profile. Dalam upaya pembuatan media promosi dan informasi dalam membuat company profile bebentuk desain booklet dengan menggunakan aplikasi Photoshop CS5 ini perlu dilakukan studi pustaka sebagai salah satu dari penerapan metode penelitian yang dilakukan. Berikut ini adalah 10 penelitian yang telah dilakukan dan memiliki kolerasi yang searah dengan penelitian yang akan dibahas dalam Jurnal ini diantaranya :

1. Penlitian yang dilakulan oleh Erna Susanti pada tahun 2013 penelitian ini berjudul "Enriching Company ProfileSebagai Penunjang MediaInformasi dan Promosi Pada Perguruan Tinggi Raharja”. Dalam hal ini, konsep media apa yang dilakukan penelitiberupapengembangan media informasi dan promosi yang berbentuk buku company profile berukuran $21 \times 29.7 \mathrm{~cm}$. Buku company profile tersebut bertujuan untukmemberikan nilai lebih dalam menerapkan strategi pemasaran, dengan harapan dapat berguna dan memiliki nilai tambah dalam media informasi dan promosi pada Perguruan Tinggi Raharja.

2. Penelitian yang dilakukan oleh Ratna Arica Rina, Ayu Fiska Nuryanpada tahun 2012penelitian ini berjudul "Pembuatan Company Profile Berbasis Multimedia FlashPD BPRBank Daerah Karanganyar". Penelitian ini berupa bagaimana membuat company profile PD BPR Bank Daerah Karanganyar menggunakan multimedia flash. Penelitian ini dibatasi pada pembuatan company profile PD BPR Bank Daerah Karanganyar menggunakan adobe flash. Adapun dari tujuan dari penelitian ini mengenai company profile PD BPR Bank Daerah Karanganyar yang berbasismultimedia flash untuk mempromosikan PD BPR Bank Daerah Karanganyar kepada masyarakat luas. Metodologi penelitian yang digunakan adalah Observasi, Keputusan, Wawancara, Analisis, Perancangan, Editing dan Impleompany profile, Editing serta implementasi. Hasil yang dicapai dalam penelitian adalah Company Profile berbasis multimedia flash PD BPR Bank Daerah Karanganyar yang diharapkan dapat digunakan sebagai sarana promosi dan informasi. Kata kunci : profil perusahaan, multimedia.

3. Penelitian yang dilakukan oleh Dewi Tresnawati pada tahun 2013 penelitian ini berjudul "Perancangan Aplikasi Multimeda Interaktif Company Profile Genetic (Studi Kasus CV. 
GANETIC)". Penelitian ini agar bagaimana perancangan ini diharapkan menjadi sebuah solusi untuk mengenalkan kepada dunia luar tentang profil organisasi/ perusahaan/ instansi swasta/pemerintah tentang pelayanan yang dilakukan, riset produk, produk yang telah dibuat maupun jasa yang diberikan dengan cara interaktif yang mudah diserap dan di ingat mengenai profile tersebut. Multimedi interaktif dibuat menggunakan metodologi pengembangan multimedia versi Sutopo-Lither merupakan aplikasi secara genetic agar pengguna bias merubah kontensesiau dengan kebutuhan baik untuk merubah teks, menu,logo, background, gambar, maupun video maka aplikasi ini bisa di gunakan ulang oleh perusahaan - perusahaan lainnya.

4. Penelitian yang dilakukan oleh Moh. Alif Cindi Momintan pada tahun 2013 penelitian ini berjudul "Perancangan Company Profile The geek Apple Authorised Reseller Yogyakarta Berbasis Multimedia Flash Sebagai Sarana Promosi dan Informasi”.Penelitian ini adalah sarana pendunkung company profile yang berbasis multimedia flash sehingga biasadijadikan salah satu media promosi bagi The Geek Apple Authorised Reseller dan sebagai media untuk menyampaikan informasi kepada masyarakat. Disamping itu juga, Company Profile berbasis multimedia flash ini bisa dijadikan alternatif lain dari media promosi lainnya seperti brosur.

5. Penelitan yang dilakukan oleh Brian Nusual Karyana Murti pada tahun 2016 penelitian ini berjudul "Rancang Bangun Company Profile Berbasis Web Untuk Efisensi Penyajian Informasi Pada SMA Antartika Sidoarjo" . Penelitian ini adalah bagaimana Company Profile mempunyai peran penting sebagai sarana promosi bagi publik tentang jati diri sebuah sekolah tersebut sehingga sebuah web sekolah menjadi menarik. Website Company Profile SMA Antartika Sidoarjo sejak dibuat belum pernah melakukan evaluasi terhadap website yang dapat mempengaruhi calon peserta didik baru dalam memilih sekolah.

6. Penelitian Tom Seward pada tahun 2012 penellitian ini berjudul "Creating a Good Company Profile". To conduct research on another firm or company for the purpose of creating a company profile of that organization. The research necessary to create a useful company profile can be time-consuming. This article provides a framework for crafting an effective company profile, as well as a list of resources to draw on for research.

7. Penelitian Igor Mozetic pada tahun tahun 2006 penelitian ini berjudul "Automated Structuring of Company Profiles" Selection of partners with appropriate competencies, resources and skills is one of the crucial tasks in the creation of virtual organizations. selection can be facilitated by structuring competencies in an ontology which provides a shared conceptualization. Manual ontology construction is a time and resource consuming activity. Alternatively, there are text mining, conceptual clustering and visualization tools available that can be used for semi-automated ontology creation. This paper proposes a methodology and presents tools which facilitate competency structuring from unstructured company data. These tools have been applied to the reconstruction of the Yahoo! business ontology.

8. Penelitian Sang Chul Jung pada tahun 2014 penlitian ini berjudul "The Analysis of Strategic Management of Samsung Electronics Company through the Generic Value Chain Model" Methodology - This paper employs a single case design to gain an in-depth understanding. The case study is the methodology when the focus is on a contemporary phenomenon within a real-business context. Findings - The findings reveal that Samsung 
electronic uses a number of the generic value chain model in creating a shared vision, establishing a performance-based personnel management system, technology development, logistics, marketing and sales, and cost control procedures. The success of the company's change effort is largely attributed to leadership, standardization of management systems, commitment to innovative strategies and training, and partnership with value chain experts.

9. Penelitian Sang H. Lee, Bang College of Business, KIMEP, Almaty, Kazakhstan Mohammad Mujibul Haque, Bang College of Business, KIMEP, Almaty, Kazakhstan pada tahun 2011 penelitian ini berjudul "The Asymmetric cyclical Effects of Bank Capital On Bank Lending: Evidences From Six Cis Countries" This paper examines the impact of government payment system on investments in oil and gas production. It shows that the expected value of an investment in oil and gas depends on the expected rate of return and risk on oil production which is impacted by the government payment system. The results indicate that the investor will exhibit a less risk-averse behavior following an increase in the price per barrel of crude oil as expected gains will cushion any subsequent losses. Contrarily, the investor will exhibit a more risk-averse behavior after a decrease in the price per barrel of crude oil. The variation in risk aversion makes returns to be volatile and the extent of the volatility will depend both on the investor's prior gains or losses.

10. Penelitian Deepak Rathod, Ranjana Khandare and Asutosh Kumar Pandey pada tahun 2012 penelitian ini berjudul "Electrical Energy Audit(A Case StudyOf Tobbaco Industry)" Company Profile: Energy Audit is the key to a systematic approach for decision-making in the area of energy management. It quantifies energy usage according to its discrete functions. Industrial energy audit is an effective tool in defining and pursuing comprehensive energy management program.

Setelah melakukan peninjauan terhadap sepuluh literature review yang ada, telah banyak penelitian mengenai pembuatan company profile dan untuk meningkatkan metode company profile berbentuk desain booklet menggunakan aplikasi photoshop cs5. Karena PT. Citra Surya Selaras menerangkan media promosi dan informasi yang diterapkan sacara sederhana melalui websitenya dan belum membuat company profile berbentuk buku dan oleh karena itu penulis melakukan penelitian tentang company profile berbentuk desain booklet untuk meningkatkan fasilitas pada perusahaan. Karena itu penulis membahas hal "Media Company Profile Berbentuk Desain Booklet Menggunakan Aplikasi Photoshop CS5 Di PT. Citra Surya Selaras Berbasis Multimedia" agar dapat meningkatkan media promosi dan informasi secara jelas dan dapat dilihat langsung. 


\section{IMPLEMENTASI}

\section{Skema Alur Kerja}

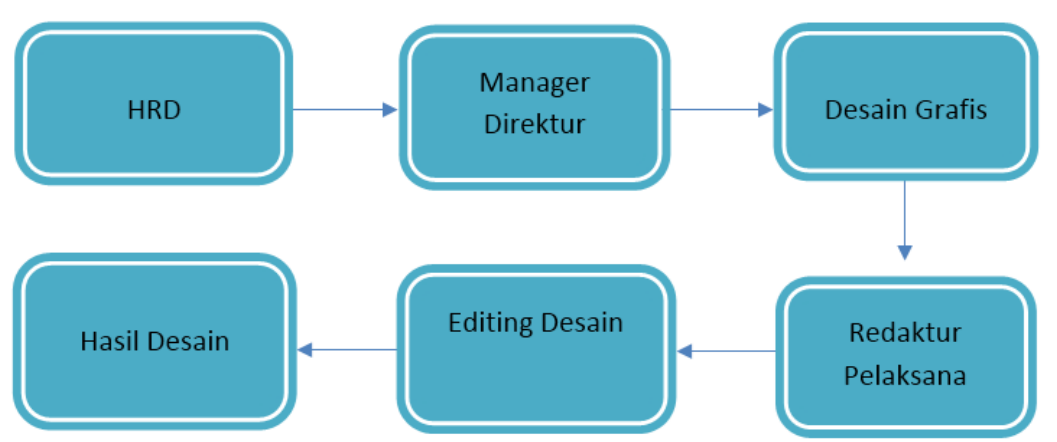

Gambar 1. Diagram blok rangkaian

\section{Multimedia Audio Visual Dan Broadcasting}

\section{Definisi Multimedia}

Multimedia adalah suatumedia yang didalamnya terdapat perpaduanberbagai bentuk elemeninformasi, seperti teks, graphics, animasi, video, interaktif maupun suarasebgai pendukung untuk mencapai tujuannya yaitu dalam menyampaikan informasi.

\section{Definisi Desain}

Desain digunakan untuk hasil akhir dari sebuah proses kreatif, baik itu wujud seperti sebuah rencana, proposal atau berbentuk benda nyata.

\section{Pengertian Storyboard}

Storyboard adalah berbentuk sketsa gambar yang berurutan

\section{Konsep Desain}

Cover halaman depan.

a. Layout jadi

Cover halaman depan sangat penting karena bentuk awal dalam sebuah buku atau katalog, dalam company profile berbentuk desain booklet ini cover depan harus berisi logo perusahaan dan nama perusahaan. 


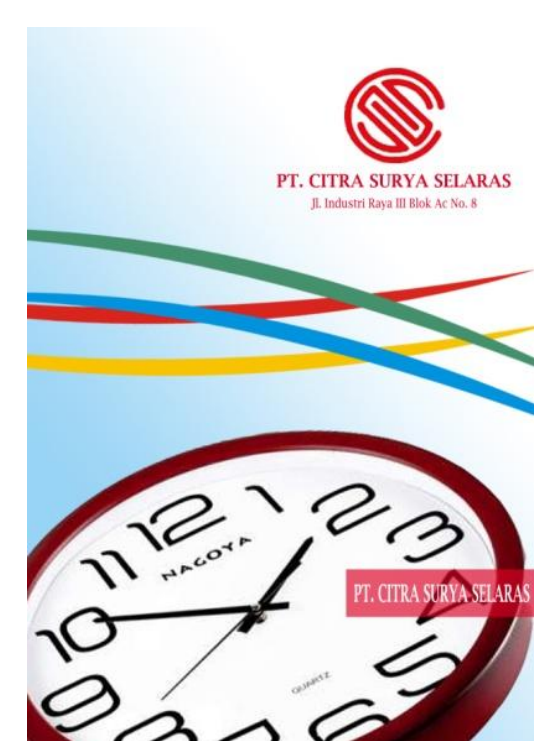

\section{Gambar 1. Cover halaman depan company profile}

Spesifikasi : Ukuran Media : 21 x 29,7 cm

Bahan: Art Paper150gram

Kata pengantar halaman kedua.

b. Layout jadi

Kata pengantar sangat penting dalam pembuatan company profile karena dalam company profile kata pengantar adalah sebuah sambutan dari direktur perusahaan.

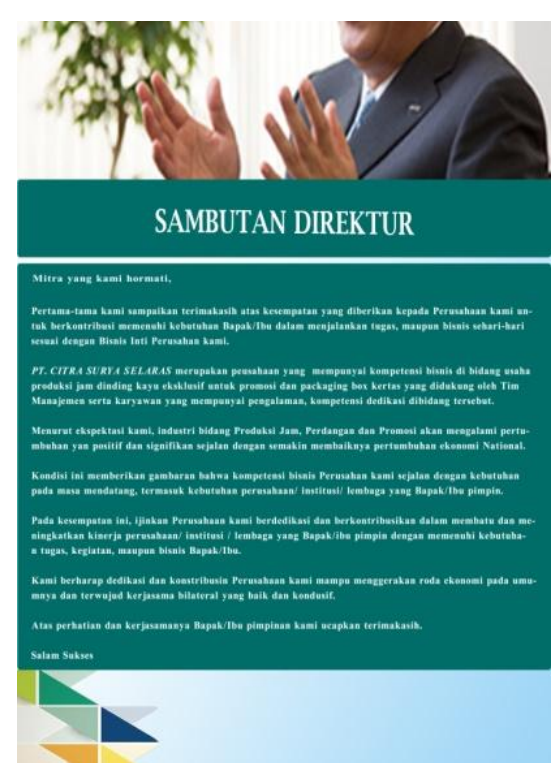

Gambar 2. Halaman kedua company profile kata pengantar

Spesifikasi : Ukuran Media : 21 x 29,7 cm

Bahan: Art Paper 150 gram

Sejarah singkat serta visi dan misi perusahaan.

c. Layout jadi

Sejarah singat serta visi dan misi perusahaan sangat penting dalam pembuatan company profile. 


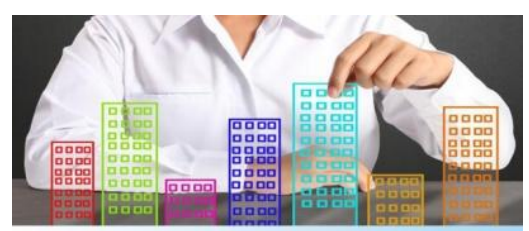

SEARAH BERDIRIVYA PERTSSHAAI

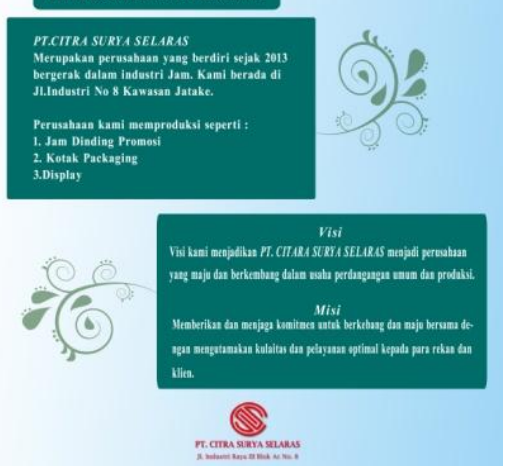

Gambar 3. Halaman ketiga company profile sejarah singat serta visi dan misi

Spesifikasi : Ukuran Media : 21 x 29,7 cm

Bahan: Art Paper 150 gram

Produk/jasa perusahaan.

d. Layout jadi

Produk/jasa perusahaan juga bagian penting dalam pembuatan company profile karena berisi apa saja yang di tawarkan oleh perusahaan dan menjual produk apa saja.

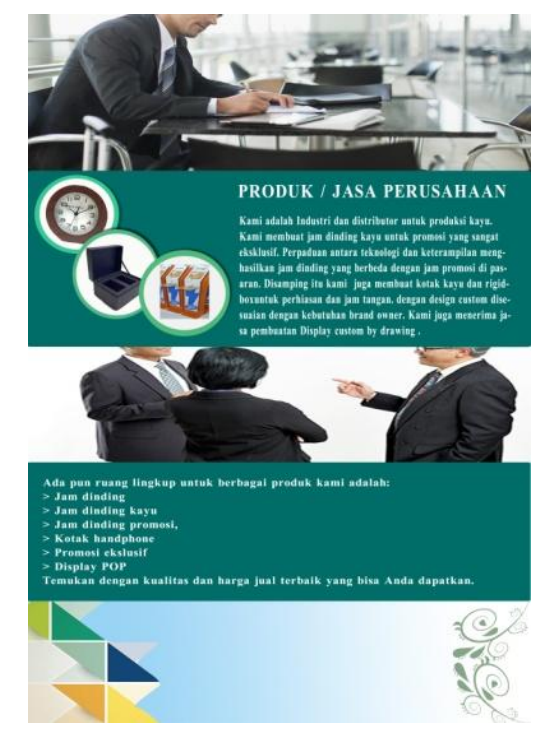

Gambar 4. Halaman keempat company profile produk/jasa perusahaan

Spesifikasi : Ukuran Media : 21 x 29,7 cm

Bahan: Art Paper 150 gram

Website perusahaan.

e. Layout jadi 
Penjelasan tentang halam website yang di buat oleh perusahaan adalah bagian penting dalam pembuatan company profile karena berisi tentang penjualan produk.

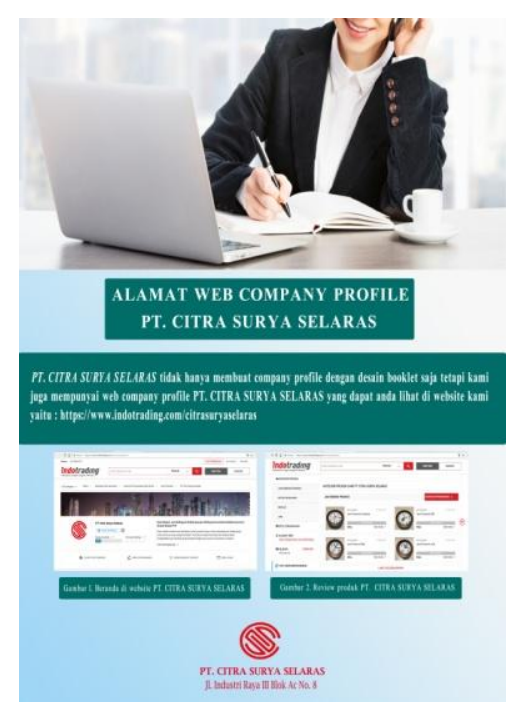

Gambar4. Halaman keempat company profile website perusahaan

\section{Spesifikasi : Ukuran Media : 21 x 29,7 cm \\ Bahan: Art Paper 150 gram}

Cover halaman belakang.

f. Layout jadi

Cover halaman belakang sangat penting untuk bagisn desain buku maupun katalog, dalam company profile cover belakang berisi logo perusahaan, alamat, nomer telepon, email dan sebaginya.

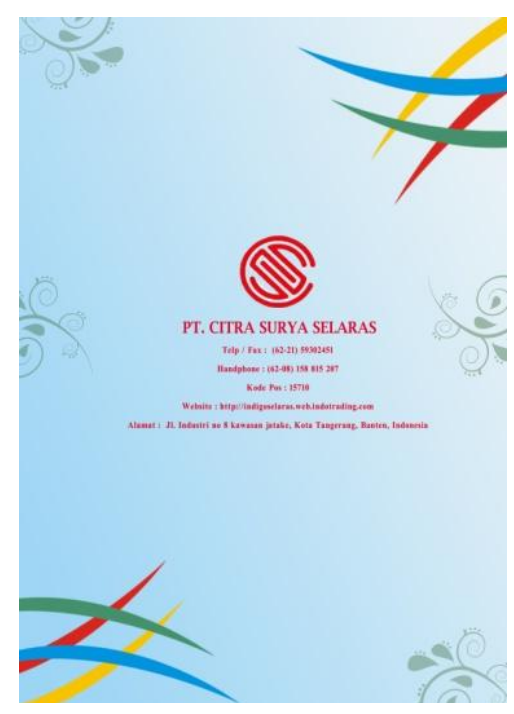

Gambar 5. Cover halam belakang company profile

Spesifikasi : Ukuran Media : 21 x 29,7 cm

Bahan: Art Paper 150 gram 


\section{KELEBIHAN COMPANY PROFILE}

Memudahkan perusahaan dalam menjelaskan media promosi dan informasi company profile yang telah dilakukan dalam bentuk desain booklet. Perusahaan tidak perlu berusah payah untuk meceritakan tentang perusahaan tapi dengan mudah perusahaan dapat memberikan media promosi dan informasi melalui company profile dalam bentuk desain booklet. Identifikasi menjadi lebih mudah, cepat dan akurat serta efisiensi perusahaan pun akan meningkat karena adanya media promosi dan informasi secara memluai buku ini lebih terpercaya arsip dan pekerjaan dapat di minimalisir. Adanya notifikasi yang memungkinkan pimpinan dapat mengetahui informasi saat itu juga.

\section{KELEMAHAN COMPANY PROFILE}

Masih banyak prusahaan yang jarang memakai company profiledalam bentuk desain booklet karena hanya menganggap comany profile biasa sehingga bisa kesulitan dalam mencari media promosi dan informasi.

\section{KESIMPULAN}

Dengan demikian dapat disimpulkan, penelitian ini menggunakan metode Aplikasi Photoshop Cs5. Menggunakan sistem company profile berbentuk desain booklet agar lebih efisien, aman, nyaman dan cepat diterapkan pada PT. Citra Surya Selaras sebelumnya. Pengembangan sitem company profile memudahkan masyarakat dalam mencari media promosi dan informasi. Sistem company profile ini sangat efisien untuk masyrakat karena mudahnya company profile jika ingin mencari media promosi dan informasi. Dengan menggunakancomany profile menjadi lebih aman, efektif karena masyarakat tidak perlu kesulitan untuk mencari media promosi dan informasi, Dengan adanya sistem company profie pada PT. Citra Surya Selaras diharapkan dapat memberikan kemudahan masyrakat dalam melakukan informasi yang disajikan akurat, cepat serta efisien.

\section{DAFTAR PUSTAKA}

[1] Erna Susanti. 2013. "Enriching Company Profile Sebagai Penunjang Media Informasi Dan Promosi Pada Perguruan Tinggi Raharja". Tangerang: Perguruan Tinggi Rahraja Vol. 7, No., September 2013.

[2] Ratna Arica Rina, Ayu Fiska Nuryna. 2012. "Pembuatan Company Profil Berbasis Multimedia Flash PD BPR Bank Daerah Karanganyar”. Sentra Penelitian Engineering dan Edukas. Vol. 4, No. 2, 2012.

[3] Dewi Tresnawati. 2012. "Perancangan Aplikasi Multimeda Interaktif Company Profile Genetic (Studi Kasus CV. GANETIC)”. Garut: Sekolat Tinggi Teknologi Garut. Vol. 1, No. 9, 2012.

[4] Moh. Alif Cindi Momintan1,Rizqi Sukma Kharisma 2013. "Perancangan Company Profile The Geek Apple Authorised Reseller Yogyakarta Berbasis Multimedia Flash Sebagai Sarana Promosi dan Informasi".Yogyakarta: Teknik Informatika STMIK AMIKOM Yogyakarta. Vol. 14 No. $04,2013$.

[5] Brian Nusual Karyana Murti , Bambang Hariadi, Rahayu Arya Shintawati. "Rancang Bangun Company Profile Berbasis Web Untuk Efisensi Penyajian Informasi Pada SMA Antartika Sidoarjo”. Surabaya: Institut Bisnis Dan Informatika Stikom Surabaya. Vol. 5, No. 12, 2016. 
[6] Joni Susi. 2015. “Menggunakan Company Profile Untuk Menggaet Investor”. Jakarta: Universitas Esa Unggul . Vol. 11, No.2, Maret 2015.

[7] Rizkhy .2011. "Heikelmedia Corporation Company Profile" Bandung: UNIKOM. Vol.13, No.1, September 2011.

[8] Tom Seward. (2012). "Creating a Good Company Profile". Reproduced by permission. Vol. 41, No. 5, May 2012.

[9] Igor Mozetic.2006.http://ponta.ijs.si/mozetic/papers/Ljubicetal-ComProf-MetZv06.pdf”'Automated Structuring of Company Profiles"..Metodoloski zvezki. Vol. 3, N0. 2 , 2006.

[10]Sang H. Lee, Bang College of Business, KIMEP, Almaty, Kazakhstan Mohammad Mujibul Haque, Bang College of Business, KIMEP, Almaty, Kazakhstan. 2011. "The Asymmetric cyclical Effects of Bank Capital On Bank Lending: Evidences From Six Cis Countries". JIF., Vol. 11, .No. 1, 2011. 